\title{
Mirtazapine in Paroxetine Induced Hyper-prolactinemic Galactorrhoea
}

\author{
Manjeet Singh, Zeeshan Anwar, Vishal Sinha, Vipin Narwal, Sayantanava Mitra, Abhishek Bharti, Ashwani Kumar \\ Mishra \\ Department of Psychiatry, Sarojini Naidu Medical College, Agra, India
}

\section{TO THE EDITOR}

Selective serotonin reuptake inhibitors (SSRIs) are commonly used to treat a gamut of depression-anxiety-spectrum disorders. Paroxetine is preferred in cases with co-existent anxiety because of its sedating properties. One problematic side-effect of all SSRIs is galactorrhea, ${ }^{1,2)}$ secondary to raised prolactin levels, which might compromise treatment of index symptoms and impose additional morbidity.

A 48-years old, postmenopausal housewife, with nil contributory family/past medical/past psychiatric or substance related history; hysterectomy with bilateral salpingo-oophorectomy (for fibroid-uterus) one year ago; presented to us with chief complaints of low mood, feeling anxious, restlessness, and with decreased sleep for one year. She reported feeling sad for most of last year, with an inability to feel good in social company, family gatherings or while doing previously-pleasurable activities. She reported feeling anxious and restless for no particular reason; reduced interest in household activities and a feeling of fatigue while doing minor works, leading to gradual neglect of these. There was subjective reduction in body weight, and feeling of heaviness and generalized bodyache during this time. Her sleep time had also reduced significantly, from 6-8 hours to 3-4 hours, with difficulty in falling asleep and frequent awakenings. There was also a reduction in her libido for last one year. She was not on any hormone-replacement therapy.

On mental status examination patient was looking of her age, dressed appropriately to her socioeconomic status, but had reduced eye contact. Her motor activity was reduced, speech was coherent and relevant but with re-

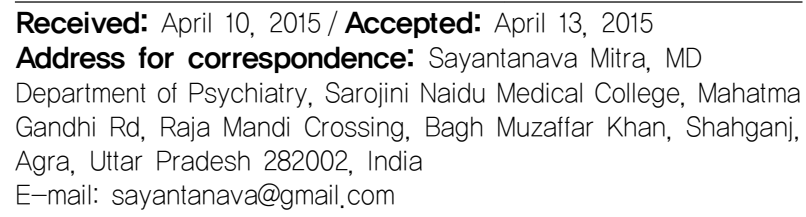

duced productivity; with depressed affect, intact abstract and judgment abilities. She reported feelings of hopelessness and helplessness. There was nil active suicidality, and Hamilton Depression Rating Scale (HAM-D) and Hamilton Anxiety Rating Scale (HAM-A) scores were $13 / 51$ and 16/56 respectively. General physical and systemic examinations were within normal limit, and brain magnetic resonance imaging was unremarkable.

She was prescribed paroxetine extended-release 12.5 $\mathrm{mg}$ at night, and advised thyroid profile. After 20 days of treatment, thyroid profile was normal. Though depressive and anxiety symptoms had improved (HAM-D, 10; HAM-A, 11), she had a fresh complain of galactorrhea for past 6 days. Prolactin level was found to be $41.31 \mu \mathrm{g} / \mathrm{L}$. Paroxetine was discontinued, and we shifted her to mirtazapine $7.5 \mathrm{mg}$ at night, hiked to $15 \mathrm{mg}$ after 7 days. In 15 days, her galactorrhea improved, and stopped over next fortnight. Her prolactin level reduced to $20.53 \mu \mathrm{g} / \mathrm{L}$, while HAM-D and HAM-A had improved to 8 each.

All SSRIs are known to cause hyperprolactenemia, but the exact mechanism is not known. Serotonin is one of the modulators affecting prolactin release in neurohypophysis; mediated directly or indirectly via stimulation of post-synaptic 5- $\mathrm{HT}_{1 \mathrm{~A}}, 5-\mathrm{HT}_{2 \mathrm{~A}}$, and $5-\mathrm{HT}_{2 \mathrm{C}}$ receptor subtypes from excess serotonin levels at the synapses. ${ }^{2,3)}$ Mirtazapine has a markedly different receptor profile, as it blocks presynaptic alpha- 2 adrenergic receptors and inhibits, rather than stimulating, postsynaptic serotonin 5- $\mathrm{HT}_{2}$ and $5-\mathrm{HT}_{3}$ receptors. ${ }^{1)}$ Therefore, mirtazapine is theoretically not expected to raise prolactin levels, and thus is unlikely to cause galactorrhea. Hence, mirtazapine may be a safe option for those unable to tolerate SSRI-associated galactorrhea, but nevertheless requiring antidepressant treatment for their symptoms.

\section{REFERENCES}

1. Stahl S. Stahl's essential psychopharmacology: neuroscientific basis and practical application. 4 th ed. Cambridge:Cambridge University Press;2013. p.298-318. 
2. Chatterjee SS, Mitra S, Mallik N. Emerging hyperprolactinemic galactorrhea in Obsessive Compulsive Disorder with a stable dose of Fluoxetine. Clin Psychopharmacol Neurosci 2015. [Eub ahead of print]
3. Emiliano AB, Fudge JL. From galactorrhea to osteopenia: rethinking serotonin-prolactin interactions. Neuropsychopharmacology 2004;29:833-846. 